\section{INJURY OF THE BRAIN. ANOMALOUS PHENOMENA.}

\section{To the Editor of THE LANCET.}

SIR:-The following communication may be thought sufficiently interesting to obtain a place in your useful Periodical. I am, Sir, your most obedient servant,

Thomas Frederic Crawford.

Newcastle-on-Tyne, March 5, 1840.

John Hogg, aged 45, died, during the winter of 1838, in the Tynemouth Union Workhouse, from the effects of some mischief within the head, of which the prominent signs were, feebleness of the heart's action, coldness of the surface, obstinate constipation of the bowels, coma, \&c.

On inspection, a large quantity of serum was found on the surface of the brain, unaccompanied by any mark of inflammation, either of the membranes of the brain (unless the effusion be regarded as such), or of the substance of the brain itself.

The Brain was very carefully examined, and between the thalamus opticus, and corpus striaturn of each side, a cyst, containing serum, was found, the walls of which were very firm. Each cyst might be capable of containing a scarlet or kidney bean, and each was evidently the remains of, or a change succeeding to, a quantity of effused blood.

On inquiry into the history of John Hogg, I found that, five years before his death, he had had an attack of apoplexy, from which he recovered in course of time, having, however, after this, to contend with one of its results, viz., hemiplegia of the right side; when nearly restored, he was again the sub. ject of an apoplectic seizure a year afterwards: This was found to have caused a second attack of hemiplegia, again of the right, side, from which, however, he never thoroughly recovered.

Remarks. - Of course we must regard each of these apoplectic seizures, and each of the attacks of hemiplegia, as connected with an effusion of blood, the result of which was the cyst seen on eacb side of the brain; it is difficult, however, to say which side of the brain suffered first, as a sufficient number of cases is recorded to show that hemiplegia may occur on the same side where the blood has been poured out. And it is still more difficult to account for the occurrence of the hemiplegia of one side only, when both sides of the brain were injured. Perhaps the right side of the body having been the side affected, and in consequence a weak side, became affected a second time, when the circulation through the brain was disturbed. This, I allow, is but a sorry explanation, but it is the best $I$ have to offer.

\section{VACCI N A T I O N.}

Lord Ellengorough has brought in a Bill, which was read for the first time in the House of Lords on March 12th, with the object of encouraging the practice of vaccination. The Bill is entitled "An Act to Extend the Practice of Vaccination :"-

1. Whereas it is expedient to extend the practice of vaccination, be it therefore enacted, \&c., that from and after the passing of this .ct it shall be lawful for the guardians of every Poor-Law Union in England and Wales, and they are hereby directed, to contract with the medical officers of their several Unions respectively for the vaccination of all children who may be brought to them for that purnose.

2. That such guardians shall, after consultation with such medical officers, from time to time appoint and give due notice of the appointment of such, and to so many convenient places and times as to them may seem fit, at which such medical officers shall attend to vaccinate all children who may be brought to them for that purpose; provided always that not more than three calendar months shall in any case elapse between the times at which such medical ufficers shall so attend.

3. That such medical officers shall make a report to the guardians of the several Poor-Law Unions in which they may act respectively on the next day of the meeting of such guardians after every such time so appointed as aforesaid for the vaccination of children, of the number of children then vac. cinated, and from time to time shall make such further report with respect to the children so vaccinated, as the guardians of the several Poor-Law Unions, under the direction of the Poor-Law Commissioners, shall require.

4. This clause gives certain powers to guardians as to medical contracts.

5. That every such medical person shall give the like attendance and make the like reports as is and are hereinbefore required from the medical officer of any Union.

6. This clause provides that the guardians are to transmit a copy of every contract to the Poor-Law Commissioners, who may annul the same, \&c.

7. This clause enacts that the Guardians of the Poor-Law Unions in Ireland are to divide their Unions into districts, \&c.

8. That all the provisions hereinbefore made with respect to the Poor.Law Unions in England and Wales, for the appointment and giving due notice of the appointment of the places and times at which such medical officers or persons shall attend to vaccinate such children, and for the making of reports 